\title{
Aplikasi Monitoring Air Pada Water Torn Secara Otomatis Berbasis Android dan Di Dukung Oleh Mikrokontroller
}

\author{
Andre Febrian Kasmar ${ }^{1 *}$, Fanni Sukma ${ }^{2}$, Dwiny Meidelfi ${ }^{3}$ dan Anggie Meyfrian Pratama ${ }^{4}$ \\ 1,2,3,4 Jurusan Teknologi Informasi, Politeknik Negeri Padang, J1. Limau Manih Padang, 25164, Indonesia \\ *Corresponding Author, email:dwinymeidelfi@pnp.ac.id
}

\begin{abstract}
Abstrak - Kendali dan monitoring air dalam sebuah tangki merupakan satu intrumentasi komputer yang diperlukan di industri. Penelitian ini membahas tentang aplikasi monitoring air pada water torn secara otomatis berbasis android dan didukung oleh mikrokontroller. Salah satu bidang teknologi yang berkembang ialah teknologi mikrokontroller, dalam perancangan alat ini, menggunakan mikrokontroller NodeMCU sebagai pengolah data dan sensor ultrasonik sebagai input data serta buzzer, dan servo. Sensor ultrasonik merupakan suatu perangkat yang dapat mengukur jarak suatu objek dengan memanfaatkan pantulan gelombang ultrasonik. Monitoring air ini menggunakan firebase sebagai database untuk menyimpan data. Untuk menampilkan data pengukuran, perangkat antar muka dirancang pula dengan menggunakan perangkat lunak aplikasi android studio dalam bentuk grafik, status pompa, dan notifikasi air. Hasil pengujian menunjukan bahwa sensor ultrasonik yang digunakan mampu mengukur ketinggian air dari $2 \mathrm{~cm}$ sampai 20 cm dengan rata-rata kesalahan pengukuran 4,93\%. Monitoring air yang dirancang mampu menghasilkan respon keluaran sistem sesuai dengan nilai referensi yang diberikan. Sebagai tambahan, monitoring ketinggian muka air dapat ditampilkan pada perangkat lunak android secara interaktif.
\end{abstract}

Kata kunci : Mikrokontroller NodeMCU, Sensor Ultrasonic HC-SR04, Servo, Buzzer.

\begin{abstract}
Abstrack - Control and monitoring of water in a tank is a computer instrumentation needed in industry. This research discusses a water monitoring application in water torn automatically based on android and supported by a microcontroller. One of the developing technology fields is microcontroller technology. In designing this device, it uses a NodeMCU microcontroller as a data processor and an ultrasonic sensor as data input as well as a buzzer and servo. An ultrasonic sensor is a device that can measure the distance of an object by utilizing reflected ultrasonic waves. This water monitoring uses firebase as a database to store data. To display measurement data, the interface is also designed using the Android Studio application software in the form of graphs, pump status, and water notifications. The test results show that the ultrasonic sensor used is able to measure water levels from $2 \mathrm{~cm}$ to $20 \mathrm{~cm}$ with an average measurement error of $4.93 \%$. Water monitoring is designed to be able to produce a system output response according to the reference value given. In addition, water level monitoring can be displayed on the Android software interactively
\end{abstract}

Keywords: Microcontroller NodeMCU, Sensor ultrasonic HC-SR04, Servo, Buzzer

(C) 2020 Elektron Jurnal Ilmiah

\section{I.PENDAHULUAN}

Seiring dengan perkembangan teknologi yang sangat pesat pada akhirnya mengantarkan pada suatu era teknologi yang telah membuat kualitas kehidupan manusid semakin tinggi. Perkembangan ilmu pengetahuan dan teknologi khususnya dalam bidang teknologi informasi telah membawa perubahan besar dalam tatanan kehidupan manusia, dimana hampir seluruh seluruh kegiatan manusia tidak dapat dipisahkan dari bidang yang satu ini baik secara langsung maupun tidak langsung. Teknologi hasil peradaban manusia yang semakin maju, dirasakan sangat membantu dan mempermudah manusia dalam memenuhi kebutuhan hidupnya dizaman modern seperti sekarang ini. Saat ini, telah banyak dibuat berbagai peralatan yang mendukung kinerja manusia, mulai dari alat-alat kontrol sederhana dengan berbasis teknologi yang rumit.

Salah satu teknologi yang berkembang dalam bidang elektronika adalah mikrokontroller. Mikrokontroler adalah komponen sebuah chip yang dapat melakukan pemrosesan data secara digital sesuai dengan perintah Bahasa pemograman yang diberikan, Salah satu contoh penerapan dibidang teknologi adalah monitoring air secara otomatis pada water torn berbasis android dan mikrokontroller.

Pengawasan terhadap ketinggian air baik pada bak tangki ataupun merupakan pekerjaan yang tidak terlalu sulit, namun jika terjadi kelalaian dalam pengawasan akibatnya sangat merugikan karena menyangkut ketersedian air yang mulai menipis saat ini dan masa yang akan datang. Bukan hanya itu, informasi ketinggian air pada bak tangki juga tidak ada saat ini. Sehingga ketika bak penuh dan melimpah, pengguna tangki tidak cukup waktu untuk mematikan alat tersebut. Rata-rata meraka tidak tahu kapan bak penampungan tersebut akan penuh. Di perumahan ditengah kota atau apartemen biasanya memakai bak water torn yang di letakkan diatas puncak rumah.

Penelitian tentang monitoring air sudah ada yang melakukan, diantaranya penelitian yang dilakukan oleh [1] Tujuan penelitian ini mempelajari prinsip kerja 
sensor ultrasonik, rangkaian Arduino dan motor servo. Fungsi Arduino pada rangkaian dipenelitian dapat mengendalikan input dan output berupa motor servo yang akan membuka dan menutup pintu bendungan secara otomatis berbasis web menggunakan pemrograman arduino. Sistem kerja pada penelitian ini memonitoring bendungan otomatis berbasis web pada Bendungan Irigasi di Desa G2 Dwijaya Kecamatan Tugumulyo Kabupaten Musi Rawas dan untuk pengendalian Bendungan otomatis menggunakan sensor kekeruhan air di olah oleh mikrokotroller arduino uno danketinggian air di ukur dengan sensor ultrasonik kemudian diolah pada mikrokontroller arduino uno dan ditampilkan melalui halaman web. Selanjutnya penelitian yang dilakukan oleh [2] membahas tentang sistem kendali dan monitoring ketinggian air pada suatu tangki berbasis sensor ultrasonik. Sensor ultrasonik merupakan suatu perangkat yang dapat mengukur jarak suatu objek dengan memanfaatkan pantulan gelombang ultrasonik. Sistem kendali dirancang menggunakan relai sebagai saklar yang diatur oleh mikrokontroler dengan metode kendali histerisis. Sistem hysteresis sendiri merupakan ketergantungan masukan/input sebuah sistem, tidak hanya pada keadaannya sekarang, tetapi juga pada keadaannya pada masa lalu. Untuk menampilkan data pengukuran, perangkat antarmuka dirancang pula dengan menggunakan perangkat lunak Processing dalam bentuk grafik, diagram batang, status pompa, dan durasi pengisian/pengosongan. Hasil pengujian menunjukan bahwa sensor ultrasonik yang digunakan mampu mengukur ketinggian air dari $5 \mathrm{~cm}$ sampai 25 $\mathrm{cm}$ dengan rata-rata kesalahan pengukuran sebesar 4,93\%. Pada penelitian ini, sistem kendali dengan metode histerisis yang dirancang mampu menghasilkan respon keluaran sistem sesuai dengan nilai referensi yang diberikan tanpa menghasilkan efek perpindahan cepat pada relai. Sebagai tambahan, sistem monitoring ketinggian muka air dapat ditampilkan dalam bentuk antarmuka pada perangkat lunak Processing secara interaktif. Sistem yang dibuat pada penelitian ini menggunakan mikrokontroller NodeMCU dan menggunakan sensor utrasonik yang digunakan untuk mengetahui ketinggian air. Sistem ini juga menggunakan firebase database untuk mengirim data serta perangkat android/smartphone yang digunakan sebagai media untuk menampilkan data monitoring air dan notifikasi peringatan. Penelitian ini bertujuan untuk merancang prototype monitoring air dan membuat suatu sistem pengontrolan level permukaan air secara real time berbasis Android dan Mikrokontroller agar dapat diketahui akurasi ketinggian level air melui notifikasi yang dikirimkan dari data ketinggian air sebenarnya

\section{METODE}

Metode Penelitian yang dilakukan adalah meliputi perancangan diagram blok, perancangan hardware, perancangan software.

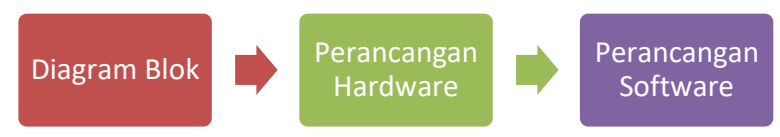

Gambar 1 Metode Penelitian

Diagram blok sebagai perancangan awal untuk menentukan hardware yang akan digunakan pada sistem monitoring air pada water torn secara otomatis. Perancangan hardware meliputi rangkaian-rangkaian sensor, mikrokontroller nodemcu, motor servo, buzzer dan driver serta modul monitoring air sebagai indikator. Perancangan software sebagai pemroses data yang melaksanakan instruksi-instruksi agar semua sistem dapat bekerja seperti yang diinginkan.

\subsection{Landasan Teori \\ A. Monitoring}

Monitoring pada dasarnya adalah pemantauan yang dapat di jelaskan sebagai kesadaran (awareness) tentang apa yang ingin di ketahui, pemantauan berkadar tingkat tinggi di lakukan agar dapat membuat pengukuran melalui waktu yang menunjukkan pergerakan ke arah tujuan atau menjauh dari itu. Sistem monitoring dirancang untuk mempermudah user berinteraksi dengan sistema yang di rancang.[2]

\section{B. Water Torn}

Tangki air adalah wadah untuk menyimpan air. Tangki air di gunakan untuk menyediakan penyimpanan air untuk di gunakan dalam banyak aplikasi, air minum, pertanian irigasi, pemadaman api, pertanian pertanian, baik untuk tanaman dan ternak, pembuatan bahan kimia, persiapan makanan serta banyak kegunaan lainnya.

\section{Android}

Android adalah sistem operasi bergerak (mobile operating system) yang mengadopsi sistem operasi linux, namun telah dimodifikasi. Android diambil alih oleh google pada tahun 2005 dari android, Inc sebagai bagian strategi untuk mengisi pasar sistem operasi bergerak. Google mengambil alih seluruh hasil kerja android termasuk tim yang mengembangkan Android.[3]

\section{Mikrokontroller NodeMCU}

NodeMcu merupakan sebuah opensource platform IoT dan pengembangan Kit yang menggunakan bahasa pemrograman Lua untuk membantu programmer dalam membuat prototype produk IoT atau bisa dengan memakai sketch dengan arduino IDE. Pengembangan Kit ini didasarkan pada modul ESP8266, yang mengintegrasikan GPIO, PWM (Pulse Width Modulation), IIC , 1-Wire dan ADC (Analog to Digital Converter) semua dalam satu board. Keunikan dari Nodemcu ini sendiri yaitu Boardnya yang berukuran sangat kecil yaitu panjang $4.83 \mathrm{~cm}$, lebar $2.54 \mathrm{~cm}$, dan dengan berat 7 gram. Tapi walaupun ukurannya yang kecil, board ini sudah dilengkapi dengan fitur wifi dan firmwarenya yang bersifat opensource.[4] 


\section{E. Firebase}

Firebase adalah suatu layanan real time database dan backend yang saat ini dimiliki oleh Google, digunakan untuk mempermudah para pengembang aplikasi dalam mengembangkan aplikasi. Firebase Real Time Database adalah fitur yang memberikan sebuah NoSQL database yang dapat diakses secara real time oleh pengguna aplikasi. Kelebihan dari firebase real time database adalah aplikasi dapat menyimpan data secara lokal ketika tidak ada akses internet, kemudian melakukan sync data segera setalah mendapatkan akses internet.[5]

\section{F. Arduino IDE}

Arduino IDE (Integrated Deveopment Environmet) adalah software yang telah disiapkan oleh arduino bagi para perancang untuk melakukan berbagai proses yang berkaitan dengan pemrograman arduino. IDE ini juga sudah mendukung berbagai sistem operasi populer saat ini seperti Windows, Mac, dan Linux. Arduino IDE merupakan Software yang digunakan untuk menulis program kedalam Arduino, tetapi walaupun dirancang untuk mikrokontroller Arduino, Software ini juga dapat digunakan untuk mikrokontroller yang lain seperti NodeMCU.[6]

\section{G. Sensor Ultrasonik HC-SR04}

Sensor ultrasonik (Gambar 1) adalah sebuah sensor yang mengubah besaran fisis (bunyi) menjadi besaran listrik. Pada sensor ini gelombang ultrasonik dibangkitkan melalui sebuah benda yang disebut piezoelektrik. Piezoelektrik ini akan menghasilkan gelombang ultrasonik dengan frekuensi $40 \mathrm{kHz}$ ketika sebuah osilator diterapkan pada benda tersebut.

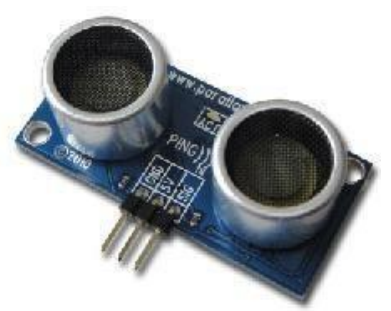

Gambar 2 Sensor Ultrasonic HC-SR04

Sensor ultrasonik memiliki 4 pin, pin Vcc, Gnd, Trigger, dan Echo. Pin Vcc untuk listrik positif dan Gnd untuk ground-nya. Pin Trigger untuk trigger keluarnya sinyal dari sensor dan pin Echo untuk menangkap sinyal pantul dari benda. Cara kerja sensor ini ialah ketika pin Trigger menerima tegangan positif selama $10 \mathrm{uS}$, maka sensor akan mengirimkan 8 step sinyal ultrasonik dengan frekuensi 40kHz. Selanjutnya, sinyal akan diterima pada pin Echo. Untuk mengukur jarak benda yang memantulkan sinyal tersebut, maka selisih waktu ketika mengirim dan menerima sinyal digunakan untuk menentukan jarak benda tersebut.
Untuk mendeteksi ketinggian air dalam suatu tangki, pada sistem ini digunakan sensor ultrasonik. Sensor dapat dipasang diatas tangki dan memancarkan gelombang ultrasonik ke permukaan air. Sensor ini menggunakan prinsip pantulan gelombang ultrasonik. Ketika gelombang ultrasonik di pancarkan oleh sensor ini dan terdapat objek yang menyebabkan gelombang tersebut terpantul, maka sensor tersebut akan memberikan data ke mikrokontroler.[7]

\section{H. Motor Servo}

Motor servo adalah sebuah perangkat actuator putar (motor) yang dirancang dengan sistem control umpan balik loop tertutup (servo), sehingga dapat diatur untuk menentukan dan posisi sudut dari proses output motor. Motor servo merupakan sebuah perangkat yang terdiri dari motor DC, serangkaian gear, rangkaian control dan potensio meter.[5]

\section{Buzzer}

Buzzer adalah sebuah komponen elektronika yang berfungsi untuk mengubah getaran listrik menjadi getaran suara. Pada dasarnya prinsip kerja buzzer hampir sama dengan loud speaker, jadi buzzer juga terdiri dari kumparan yang terpasang pada diafragma dan kemudian kumparan tersebut dialiri arus sehingga menjadi electromagnet, kumparan tadi akan tertarik kedalam atau keluar, tergantung dari arah arus dan polaritas magnetnya, karena kumparan dipasang pada diafragma maka setiap Gerakan kumparan akan menggerakan diafragma secara bolak-balik sehingga membuat udara bergetar yang akan menghasilkan suara.[3]

\section{III.ANALISIS PERANCANGAN SISTEM}

\subsection{Analisis Sistem}

Dalam analisis ini akan membahas mengenai analisis yang dilakukan untuk mengevaluasi suatu permasalahn yang akan di pecahkan pada tugas akhir ini, tugas akhir ini bertujuan untuk melakukan evesiensi terhadap perangkat keras seperti yang diketahui suatu permasalahan yaitu pengeluaran banyak biaya dalam menyediakan perangkat keras.

Sistem yang dibuat merupakan monitoring air berbasis android dan mikrokontroller yang terdiri dari beberapa komponen yaitu NodeMCU, sensor ultrasonic, ic regulator 7805, buzzer, motor servo, batarai 9volt, dan menggunakan software seperti Arduino IDE, Firebase dan Aplikasi Android Studio yang saling terintegrasi. Sistem ini berfungsi untuk mengontrol serta memonitoring air pada water torn secara otomatis berbasis android dan mikrokontroller. Kemampuan berinteraksi pada pengguna dengan mengirimkan data ke firebase dan membuka android untuk mendapatkan notice level ketinggian air pada tangki secara real-time. 


\section{A. Perangkat Keras}

Pada proses pembuatan alat monitoring air secara otomatis dibutuhkan beberapa hardware untuk mendukung agar sistem monitoring air ini dapat berjalan sesuai dengan keinginan sebagai berikut.

Tabel 1 Tabel Kebutuhan Hardware

\begin{tabular}{lll}
\hline No & NAMA ALAT & KEGUNAAN \\
\hline 1 & $\begin{array}{l}\text { Mikrokontroller } \\
\text { NodeMCU }\end{array}$ & $\begin{array}{l}\text { Development Board } \\
\text { Mikrokontroller }\end{array}$ \\
\hline 2 & Sensor Ultrasonik & $\begin{array}{l}\text { Sensor untuk mengukur tingkat } \\
\text { level ketinggian air }\end{array}$ \\
\hline 3 & Motor Servo & Pengontrol buka tutup pintu air \\
\hline 4 & IC Regulator 7805 & $\begin{array}{l}\text { Untuk mempertahankan dan } \\
\text { memastikan tegangan pada level } \\
\text { tertentu secara otomatis }\end{array}$ \\
\hline 5 & Buzzer & $\begin{array}{l}\text { Sebagai getaran suara Ketika air } \\
\text { dalam keadaan penh }\end{array}$ \\
\hline 6 & Adaptor 9A & $\begin{array}{l}\text { Sebagai sumber daya semua } \\
\text { komponen }\end{array}$ \\
\hline 7 & Kabel Jumper & $\begin{array}{l}\text { Untuk menghubungkan semua } \\
\text { komponen ke mikrokontroller }\end{array}$ \\
\hline
\end{tabular}

\section{B. Perangkat Lunak}

Pada proses pembuatan alat monitoring air secara otomatis dibutuhkan software Arduino IDE dengan Bahasa pemrograman C. Sistem monitoring air secara otomatis berbasis android menggunakan software Firebase dan Android Studio dengan Bahasa pemrograman JAVA. Untuk lebih detail dapat dilihat pada tabel berikut.

Tabel 2 Kebutuhan Software

\begin{tabular}{ccc}
\hline No & Software & Bahasa/Platform \\
\hline 1 & Arduino IDE & C \\
\hline 2 & Android Studio & JAVA \\
\hline 3 & Firebase & Database \\
\hline
\end{tabular}

\subsection{Rancangan Sistem}

Tahap perancangan sistem ini merupakan gambaran prototype dari keseluruhan sistem yang akan dibuat sehingga dapat mempermudah dalam melakukan pembuatan sistem.

\section{1) Block Diagram Sistem}

Perangkat keras yang digunakan untuk membuat prototype aplikasi monitoring air pada water torn secara otomatis menggunakan mikrokontroller NodeMCU, sensor ultrasonik. Serta firebase sebagai database secara real-time. Pemograman NodeMCU menggunakan software Arduino IDE agar antar komponen dapat saling berinteraksi. Pada Gambar 2 menjelaskan seluruh komponen yang saling terhubung dari NodeMU hingga sampai Android.

\section{2) Rancangan Rangkaian Elektronika}

Rangkaian elektronika adalah gabungan dari seluruh komponen yang memperhatikan port-port/pin komponen yang dipakai. Adapator menggunakan 9volt yang akan di konversi menjadi daya 5v. Baterai memiliki 2 kaki, yaitu out+ dan out-, out+ dari baterai

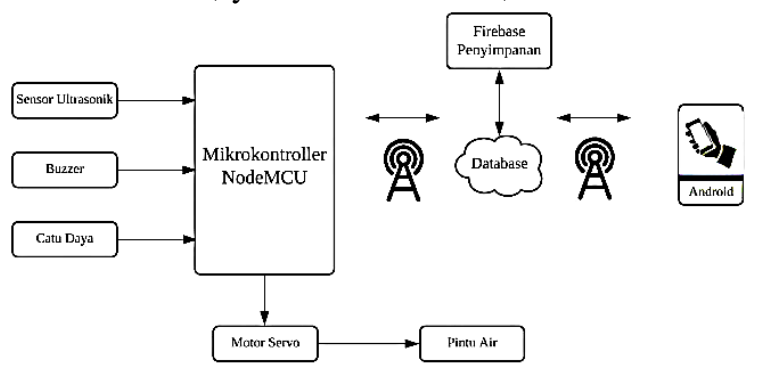

Gambar 3 Block Diagram Sistem

dihubungkan ke in+ dari converter, out- dari baterai dihubungkan ke in- dari converter. Mikrokontroller NodeMCU memiliki pin vin yang dihubungkan ke out+ dari converter dan pin gnd yang dihubungkan ke outdari converter. Pada sensor ultrasonic digunakan 4 pin yaitu vcc, ground, echo dan trig. Pin vec dihubungkan dengan out+ dari converter, pin ground dihubungkan dengan out- dari converter, pin trig dihubungkan pada pin D4 nodeMCU dan pin echo dihubungkan pada pin D3 nodeMCU.

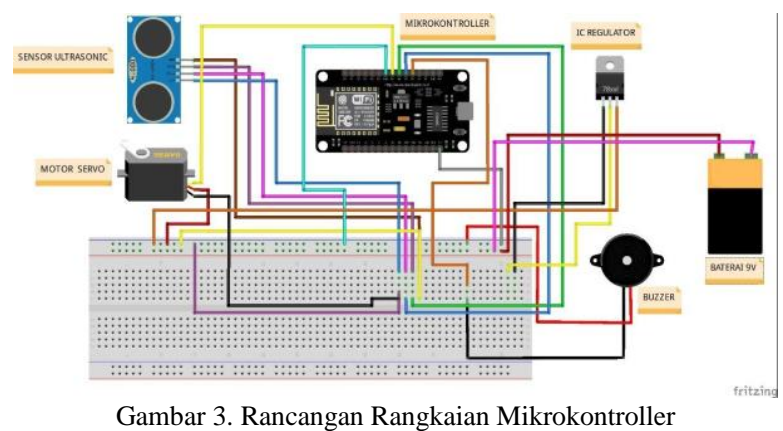

Prototype monitoring air secara otomatis berbasis android dan didukung oleh mikrokontroller dengan NodeMCU ini membentuk suatu sistem pemantauan ketinggian level air di smartphone secara otomatis yang dapat diakses dimanapun selama terdapat koneksi internet.

\section{3) Rangkaian Sistem Mikrokontroller}

Pada NodeMCU yang telah terhubung dengan sensor ultrasonik yang mengitung ketinggian air melalui perhitungan jarak antara tinggi air dari sensor dengan tinggi air sebenarnya dari tangki, nilai tinggi air dari tangki didapat berdasarkan jarak posisi sensor dari tangki. Untuk mencari jarak antara tinggi air dari sensor dengan tinggi air dari tangki menggunakan sensor ultrasonik HC-SR04 dapat dilakukan dengan rumus pada persamaan 1 .

$$
\text { Volume }=\pi \times \mathrm{r} \times \frac{\mathrm{t}}{100} \quad \text { persamaan } 1
$$

Sensor ultrasonik dapat mengukur jarak ketinggian air yang terjadi dalam satuan $\mathrm{cm}$ secara realtime. Diagam pada Gambar 4. Menunjukkan alur yang terjadi selama pengukuran ketinggian air dilakukan oleh sensor ultrasonik dengan nodeMCU dan informasi dikirimkan ketika level air terdeteksi berada pada keadaan penuh. 


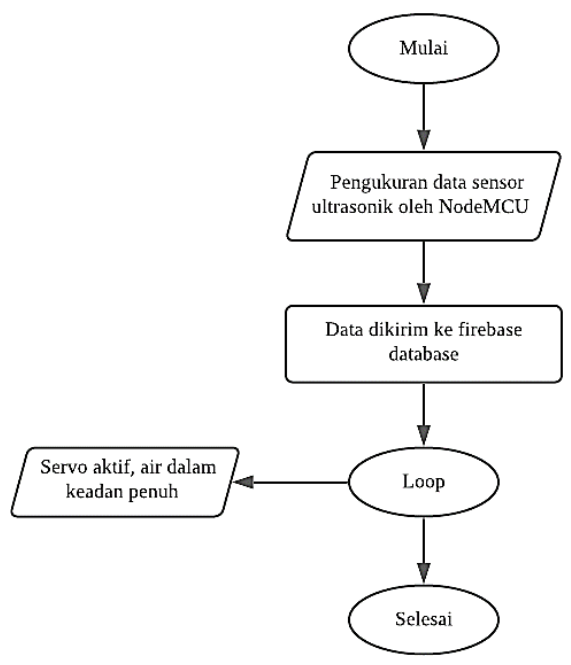

Gambar 4. Flowchart Mikrokontroller

4) Rancangan Sistem Aplikasi Android

a) Rancangan Android

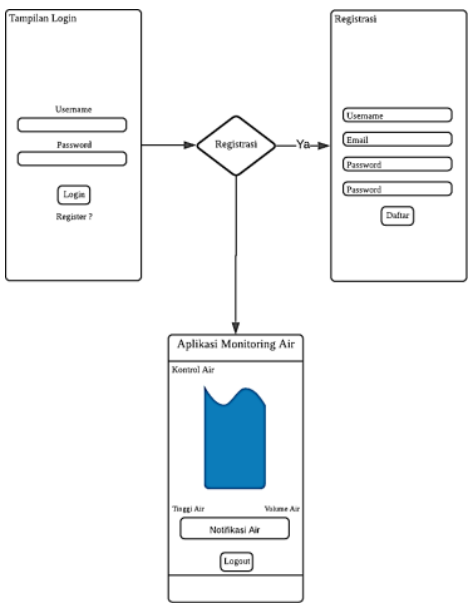

Gambar 5. Rancangan Aplikasi Android.

Gambar 5 menampilkan rancangan aplikasi android yang dibuat. Dimulai dengan halaman login. Jika belum mempunyai akun, bisa melakukan registrasi terlebih dahulu, namun jika telah mempunyai akun, bisa menampilkan kondisi air.

Tabel 3 Notifikasi Pada Android

\begin{tabular}{ccc}
\hline NO & Ketinggian Air & Notifikasi Tampil \\
\hline 1 & $1-3 \mathrm{~cm}$ & Air hampir habis \\
\hline 2 & $3-17 \mathrm{~cm}$ & Air dalam keadan norma \\
\hline 3 & $17-20 \mathrm{~cm}$ & Air penuh \\
\hline
\end{tabular}

Untuk notifikasi, ketika air kurang dari $3 \mathrm{~cm}$ maka notifikasi menampilkan "Air hampir habis". Ketika air lebih dari 3-17 cm notifikasi menampilkan "Air dalam keadaan normal, tidak perlu ada tindakan" dan Ketika air lebih dari $17 \mathrm{~cm}$ notifikasi menampilkan "Air hampir penuh, segera untuk matikan air". Untuk notifikasi dikirim secara real-time. Pada prototype ini diujikan pada torn air dengan rumus pada persamaan 1 , maka didapat perhitungan : nilai $\pi=3,14, r^{2}=14, \mathrm{t}=$ 20

\section{b) Flowchart Sistem Aplikasi}

Flowchart aplikasi android seperti dalam Gambar 6, ketika air kurang dari $3 \mathrm{~cm}$ dari jarak sensor, motor servo akan membuka dan menampilkan notifikasi pada aplikasi. Ketika air lebih dari 3-17 cm notifikasi menampilkan "Air dalam keadaan normal, tidak perlu ada tindakan" dan ketika air lebih dari $17 \mathrm{~cm}$ notifikasi menampilkan "Air hampir penuh, segera untuk matikan air".

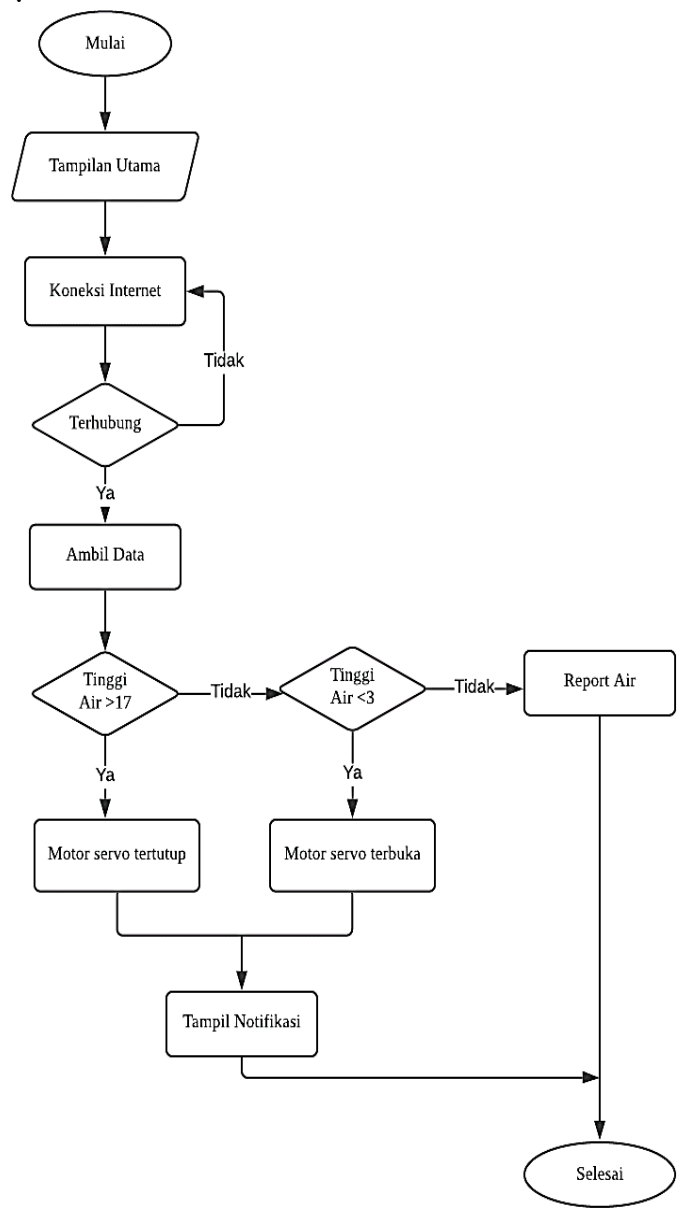

Gambar 6. Flowchart Sistem Aplikasi Android

\section{c) Perancangan Program Mikrokontroller}

Arduino merupakan pemograman Bahasa $\mathrm{C}$, yang sudah dilakukan perubahan untuk memudahkan pemula dalam melakukan pemograman Bahasa aslinya. Arduino IDE dibuat dari Bahasa pemograman JAVA yang dilengkapi dengan library $\mathrm{C} / \mathrm{C}++$ yang disebut sebagai Wiring yang membuat operasi input dan output menjadi lebih mudah. Untuk memulai klik Arduino IDE yang sudah ada pada PC/Laptop dan akan tampil seperti pada Gambar 7. 


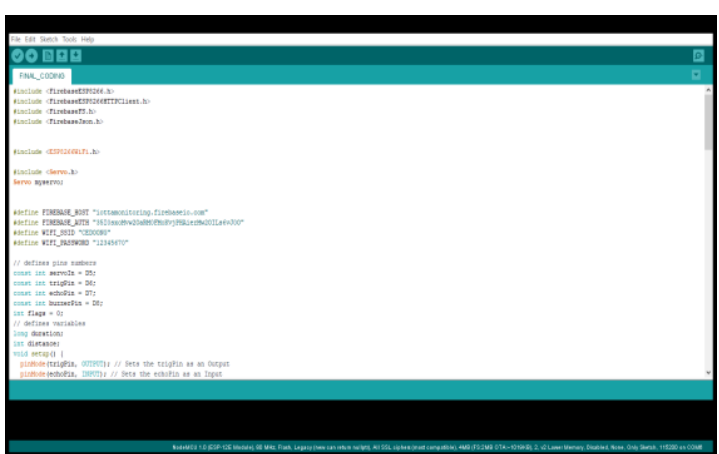

Gambar 7. Tampilan Program Arduino IDE

\section{IV.IMPLEMENTASI DAN PENGUJIAN SISTEM}

Pada tahap ini akan membahas tentang implementasi pembuatan Aplikasi Monitoring Air Secara Otomatis Pada Water Torn Berbasis Android dan didikung Mikrokontroller. Pada bagian implementasi ini menjelaskan secara detail tentang sistem yang akan dibuat mulai dari merakit, mengkonfigurasi, membangun server dan pembuatan aplikasi android serta pengujian sistem yang telah dibuat.

\section{1) Pengujian Sensor Ultrasonik}

Pengujian sensor ultrasonik menggunakan media/wadah yang berisi air dengan dua macam parameter, berisi air dan belum dipenuhi air.

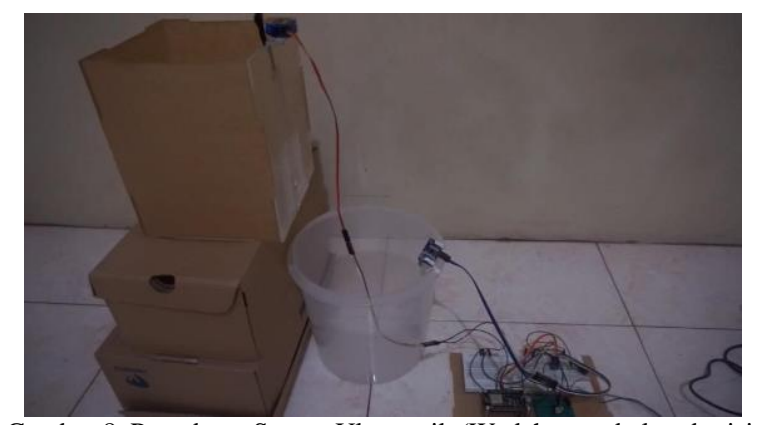

Gambar 8. Percobaan Sensor Ultrasonik (Wadah yang belum berisi ai

Pada percobaan Sensor Ultrasonik Tangki air dalam keadaan kosong seperti pada Gambar 8, nilai sensor ultrasonik menunjukan jarak air dari sensor serta tinggi air didalam tabung/tangki, hasil dapat dilihat pada serial monitor pada Gambar 9.

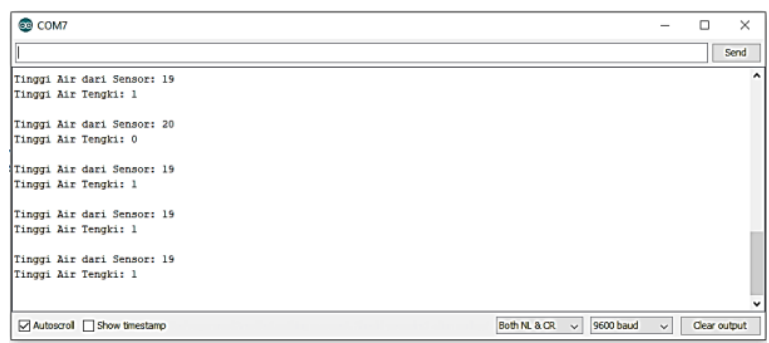

Gambar 9. Nilai Sensor Ultrasonik ketika wadah belum terisi penuh

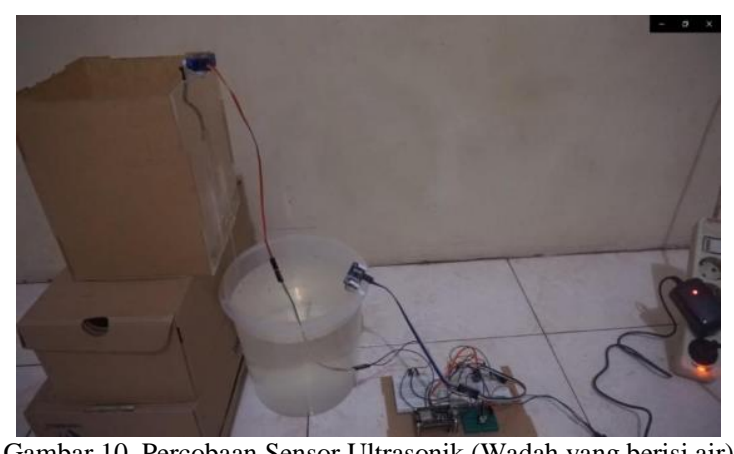

Gambar 10. Percobaan Sensor Ultrasonik (Wadah yang berisi air)

Gambar 10 menunjukkan sesnsor ultrasonik dengan wadah yang telah terisi air. Percobaaan ini dengan kondisi wadah yang terisi penuh, saat permukaan air mendekati bibir tabung dengan jarak $2 \mathrm{~cm}$, maka air tangki memiliki nilai ketinggian $18 \mathrm{~cm}$, seperti terlihat pada Gambar 11.

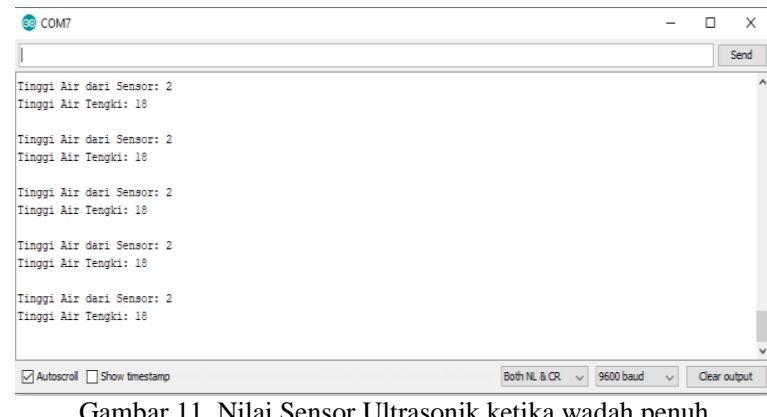

\section{2) Pengujian Data Terkirim Ke Firebase}

pengujian sensor mendeteksi permukaan air dekat dari batas atas maka data yang dikirimkan ke perangkat android melalui server pada firebase. Data yang terkirim ke firebase seperti pada gambar 12 tampil secara realtime sesuai dengan level ketinggian air pada tabung.

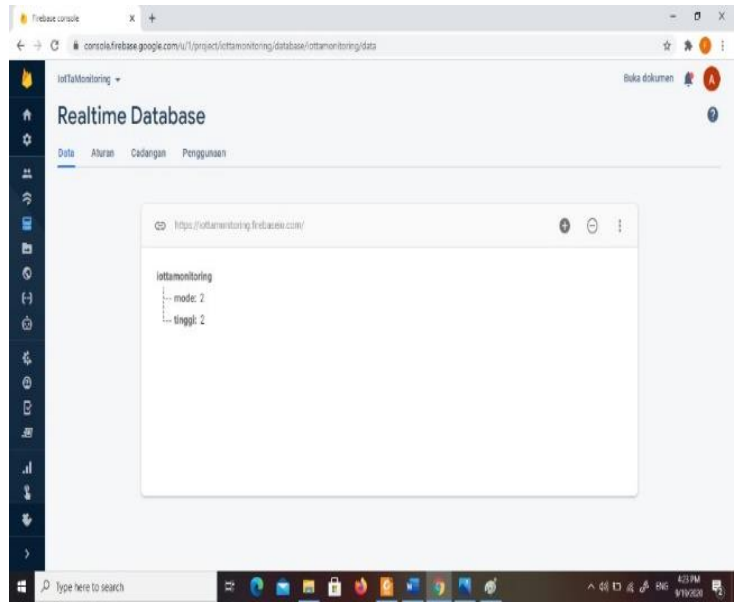

Gambar 12. Tampilan Data Terkirim Ke Firebase 
3) Pengujian Pada Aplikasi Android
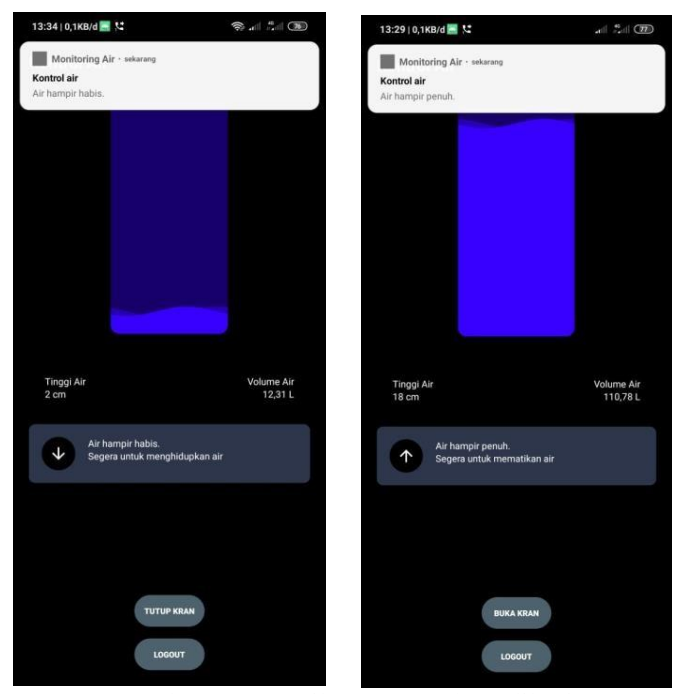

Gambar 13 Tampilan Data Pada Aplikasi

Pengujian dengan aplikasi android menggunakan data yang dikirim oleh NodeMCU melalui firebase. Aplikasi android membaca data tersebut untuk diterjemahkan kedalam tampilan GUI(Graphic User Interface) yang memberikan tampilan berupa gambar animasi tangki dalam keadaan penuh/kosong. Sesuai dengan alur ketika sensor membaca jarak air dengan pengukuran kurang dari $3 \mathrm{~cm}$ maka motor servo akan membuka untuk mengisi air, tampilan pada GUI akan memberikan notifikasi pada user bahwa "air hampir habis, segera menghidupkan air". Ketika jarak air dengan sensor kurang dari $1 \mathrm{~cm}$ maka akan tampil notofikasi "air hampir penuh, segera untuk mematikan air".

\section{4) Pengujian Sistem Secara Keseluruhan}

Setelah melakukan pengujian terhadap monitoring air diperoleh bahwa sensor ultrasonik yang dipasang dapat bekerja dengan baik ketika dilakukan pengukuran dengan level serta volume air untuk mengetahui ketinggian air dari level normal sampai dengan maksimal. Sehingga monitoring air bekerja sesuai dengan yang diharapkan. Pada pengujian sistem monitoring air ini, telah dilakukan pengujian komponen-komponen secara terpisah dan secara keseluruhan yang memberikan hasil sesuai dengan yang diharapkan ataupun yang telah diprogramkan, ketika dilakukan pengujian sensor mendeteksi permukaan air dekat dari batas atas maka data yang dikirimkan ke perangkat android melalui firebase tampil secara realtime sesuai dengan level ketinggian air pada tabung yang terlihat pada tabel 4.2.
Tabel 4.2 Data Pengujian Sistem Keseluruhan

\begin{tabular}{|c|c|c|c|c|}
\hline \multirow{2}{*}{ No } & \multirow{2}{*}{$\begin{array}{c}\text { Ketinggian } \\
\text { Air }(\mathrm{cm})\end{array}$} & \multicolumn{3}{|c|}{ Output } \\
\hline & & $\begin{array}{c}\text { Tampil } \\
\text { Firebase }\end{array}$ & $\begin{array}{l}\text { Tampil } \\
\text { Android }\end{array}$ & $\begin{array}{l}\text { Volume } \\
\text { Air }\end{array}$ \\
\hline 1 & $1 \mathrm{~cm}$ & $2 \mathrm{~cm}$ & Tampil $1 \mathrm{~cm}$ & $6,15 \mathrm{~L}$ \\
\hline 2 & $2 \mathrm{~cm}$ & $2 \mathrm{~cm}$ & Tampil $2 \mathrm{~cm}$ & $12,31 \mathrm{~L}$ \\
\hline 3 & $3 \mathrm{~cm}$ & $3 \mathrm{~cm}$ & Tampil $3 \mathrm{~cm}$ & $18,46 \mathrm{~L}$ \\
\hline 4 & $4 \mathrm{~cm}$ & $4 \mathrm{~cm}$ & Tampil $4 \mathrm{~cm}$ & $24,62 \mathrm{~L}$ \\
\hline 5 & $5 \mathrm{~cm}$ & $5 \mathrm{~cm}$ & Tampil $5 \mathrm{~cm}$ & $30,77 \mathrm{~L}$ \\
\hline 6 & $6 \mathrm{~cm}$ & $6 \mathrm{~cm}$ & Tampil $6 \mathrm{~cm}$ & $36,93 \mathrm{~L}$ \\
\hline 7 & $7 \mathrm{~cm}$ & $7 \mathrm{~cm}$ & Tampil $7 \mathrm{~cm}$ & $43,08 \mathrm{~L}$ \\
\hline 8 & $8 \mathrm{~cm}$ & $8 \mathrm{~cm}$ & Tampil $8 \mathrm{~cm}$ & $49,24 \mathrm{~L}$ \\
\hline 9 & $9 \mathrm{~cm}$ & $9 \mathrm{~cm}$ & Tampil $9 \mathrm{~cm}$ & $55,39 \mathrm{~L}$ \\
\hline 10 & $10 \mathrm{~cm}$ & $10 \mathrm{~cm}$ & Tampil $10 \mathrm{~cm}$ & $61,54 \mathrm{~L}$ \\
\hline 11 & $11 \mathrm{~cm}$ & $11 \mathrm{~cm}$ & Tampil $11 \mathrm{~cm}$ & $67,7 \mathrm{~L}$ \\
\hline 12 & $12 \mathrm{~cm}$ & $12 \mathrm{~cm}$ & Tampil $12 \mathrm{~cm}$ & $73,85 \mathrm{~L}$ \\
\hline 13 & $13 \mathrm{~cm}$ & $13 \mathrm{~cm}$ & Tampil $13 \mathrm{~cm}$ & $80,01 \mathrm{~L}$ \\
\hline 14 & $14 \mathrm{~cm}$ & $14 \mathrm{~cm}$ & Tampil $14 \mathrm{~cm}$ & $86,16 \mathrm{~L}$ \\
\hline 15 & $15 \mathrm{~cm}$ & $15 \mathrm{~cm}$ & Tampil $15 \mathrm{~cm}$ & $92,32 \mathrm{~L}$ \\
\hline 16 & $16 \mathrm{~cm}$ & $16 \mathrm{~cm}$ & Tampil $16 \mathrm{~cm}$ & $98,47 \mathrm{~L}$ \\
\hline 17 & $17 \mathrm{~cm}$ & $17 \mathrm{~cm}$ & Tampil $17 \mathrm{~cm}$ & $104,62 \mathrm{~L}$ \\
\hline 18 & $18 \mathrm{~cm}$ & $18 \mathrm{~cm}$ & Tampil $18 \mathrm{~cm}$ & $110,78 \mathrm{~L}$ \\
\hline 19 & $19 \mathrm{~cm}$ & $19 \mathrm{~cm}$ & Tampil $19 \mathrm{~cm}$ & $116,93 \mathrm{~L}$ \\
\hline 20 & $20 \mathrm{~cm}$ & $20 \mathrm{~cm}$ & Tampil $20 \mathrm{~cm}$ & $123,09 \mathrm{~L}$ \\
\hline
\end{tabular}

Dengan adanya sistem monitoring air ini, maka dihasilkan sesuatu alat pemantau tangki air pada water torn secara otomatis, yang mampu memberikan efektifitas kerja yang lebih produktif serta memberikan kemudahan bagi pengawas atau pekerja serta pegawasan pada aktifitas air dapat dipantau melalui android dan dilakukan secara otomatis.

\section{KESIMPULAN}

Pada pengujian perangkat lunak semua rangkaian dapat berfungsi dengan baik dan sesuai dengan fungsingnya. Sehingga sistem monitoring air pada water torn secara otomatis berbasis android dan mikrokontroller berhasil dirancang, diterima dan dijalankan oleh komponen. Pemanfaatan sensor ultrasonik dapat membaca jarak ketinggian air degan baik, sebagai input dan mikrokontroller NodeMCU sebagai pusat pengolahan data dari output sehingga menghasilkan output dari firebase dan android. Dengan adanya sistem monitoring air ini mendapatkan informasi ketinggian air secara real-time pada firebase database secara otomatis dan langsung mengirim data ke aplikasi Android. 


\section{UCAPAN TERIMA KASIH \\ (ACKNOWLEDGEMENT)}

Terima kasih kepada Politeknik Negeri Padang yang telah membiayai penelitian ini melalui Dana DIPA POLITEKNIK NEGERI PADANG sesuai dengan surat perjanjian Penugasan Pelaksanaan Penelitian Nomor : 208/PL9. 15/PG/2020 Tanggal 23 Juli 2020.

\section{REFERENSI}

[1] N. Lestari, "RANCANG BANGUN MONITORING BENDUNGAN OTOMATIS BERBASIS WEB PADA BENDUNGAN IRIGASI DI DESA G2 DWIJAYA KECAMATAN TUGUMULYO KABUPATEN MUSI RAWAS,” J. Sist. Komput. Musirawas, 2018.

[2] A. Alawiah and A. Rafi Al Tahtawi, "Sistem Kendali dan Pemantauan Ketinggian Air pada Tangki Berbasis Sensor Ultrasonik," KOPERTIP J. Ilm. Manaj. Inform. dan Komput., vol. 1, no. 1, pp. 25-30, 2017.

[3] Eka Rizky Yulianti, "PROTOTYPE SISTEM ALARM
BANJIR MENGGUNAKAN INTERNET OF THINGS (IOT) BERBASIS ARDUINO VIA APLIKASI ANDROID," pp. 5-10, 2019.

[4] C. D. N. Tulle, "Monitoring Volume Cairan Dalam Tabung (Drum Silinder) dengan Sensor Ultrasonik Berbasis WEB," pp. 3-9, 2017.

[5] E. B. Lewi, U. Sunarya, and D. N. Ramadhan, "Sistem Monitoring Ketinggian Air Berbasis Internet of Things Menggunakan Google Firebase," Univ. Telkom, D3 Tek. Telekomun., vol. 1, no. 1, pp. 1-8, 2017.

[6] S. J. Sokop, D. J. Mamahit, M. Eng, and S. R. U. A. Sompie, "Trainer Periferal Antarmuka Berbasis Mikrokontroler Arduino Uno," J. Tek. Elektro dan Komput., vol. 5, no. 3, pp. 13-23, 2016.

[7] S. Ultrasonik and M. Komunikasi, "SISTEM PERINGATAN DINI BANJIR AIR LAUT MENGGUNAKAN SENSOR ULTRASONIK MELALUI KOMUNIKASI SMS," vol. 3, no. 2, pp. 46-50, 2019. 